\title{
Pain Management Practices by Nurses: Application of the Self-Efficacy Theory
}

\author{
Bashar I. Alzghoul ${ }^{1} \&$ Nor Azimah Chew Abdullah ${ }^{2}$ \\ ${ }^{1}$ Respiratory Care Department, College of Applied Medical Sciences in Jubail, Imam Abdulrahman Bin Faisal \\ University-Dammam, Jubail 35816, Saudi Arabia \\ ${ }^{2}$ School of Business Management, Universiti Utara Malaysia (UUM), Kedah, Malaysia \\ Correspondence: Bashar I. Alzghoul, College of Applied Medical Sciences in Jubail, Imam Abdulrahman Bin \\ Faisal University-Dammam, Jubail 35816, Saudi Arabia. Tel: 96-655-341-4495. E-mail: bialzghoul@iau.edu.sa
}

Received: July 5, 2019 Accepted: June 6, 2020 Online Published: July 6, 2020

doi:10.5539/gjhs.v12n9p44 URL: https://doi.org/10.5539/gjhs.v12n9p44

\begin{abstract}
Pain management is one of the most recurrent healthcare services provided by nurses. Based on the proposition of the self-efficacy theory, knowledge and attitudes can affect the nurses; confidence and their ability to manage the patients' discomforts, which consequently affects their ability to apply appropriate pain management practices. The study examines the relationship between knowledge and attitudes towards distress management and the nurse's individual capability to manage pain. The research is a transverse, correlational design study involving 266 registered nurses $(\mathrm{n}=266)$. The nurses were requested to provide information on pain management via three instruments: attitude to, knowledge of and self-efficacy of pain management. Statistically, the nurses displayed an essential relationship between self-efficacy and attitude towards pain management $(\beta=0.502, \mathrm{t}=10.119, \mathrm{p}<$ 0.001 ). Also, the study discovered a substantial connection between the nurses' familiarity to pain management and their ability to manage it in patients' pain $(\beta=0.368, \mathrm{t}=6.619, \mathrm{p}<0.001)$. This study recommends that future research be undertaken to investigate the mediating effects of self-efficacy on the knowledge and attitude towards agony management relationship and distress management practices. Additionally, in future, scholars can examine the direct relationship between the effectiveness of agony control and pain management routines of nurses.
\end{abstract}

Keywords: attitude, knowledge, nurses, self-efficacy, pain management

\section{Introduction}

Distress management is an essential service for hospitalized patients. Studies have shown that 70 percent of hospitalized patients are in pain (Melotti et al., 2005; Sawyer et al., 2008). According to the International Association for the Study of Pain [IASP] (2010) and the South African Society of Anesthesiologists [SASA] (2009), the relieving of pain is an essential human right. The nurses' role in distress management includes assessing the patients' pain, by providing pharmacological and non-pharmacological interventions to relieve patients from agony and reevaluating the results after interventions ("American Nurses Association [ANA]," 2001; Khatib \& Razvi, 2018).

Consequently, inadequate pain management has led to severe complications to patients, such as increased heart rate, hypertension, resistance to the flow of blood through peripheral circulation, and formation of blood clots in the vessels (Adesoye \& Duncan, 2017; Dunwoody, Krenzischek, Pasero, Rathmell, \& Polomano, 2008). Furthermore, it has also increased patient stay in hospitals (Gan, 2017; Schechter, Berde, \& Yaster, 2003).

Based on all the above consequences, healthcare practitioners and patients agree that lack of pain management strategies causes severe health concerns (Alpert, Smith, Hummel, \& Hummel, 2017; McCaffery \& Pasero, 1999; Musgrave, 1990; Sullivan, 1994). Researchers also view it as a critical problem that should be assessed scientifically by conducting studies to help relieve the patients' agony, improve healthcare quality, and enhance patient safety.

Al-Zghoul (2016) found a significant deficiency in pain management strategies at a Jordanian hospital. The research revealed the pain management practices, such as assessment, intervention, and reassessment among Jordanian nurses is only at a moderate level. Also, Daibes (2011) discovered that Jordanian nurses lack adequate agony management skills. In particular, the strategies implemented in pain management among Jordanian medical 
practitioners are inferior and do not facilitate the patient's recovery process. Furthermore, their intervention measures do not relieve the patients from their discomfort.

Research suggests that there are three main barriers to pain management. They include defective medical systems, unskilled medical practitioners, and individual patient barriers. (Glajchen, 2001; Jacobsen, Liubarskienë, Moldrup, Christrup, Sjogren, \& Samsanaviciene, 2009; Mędrzycka-Dąbrowska, Dąbrowski, Basiński, \& Pilch, 2016; Von Roenn, 2001). The research will focus on the barrier caused by healthcare providers (knowledge, attitude, and self-efficacy) by assessing the relationship between the nurses' knowledge of pain management and their attitude towards pain management and their self-efficacy to manage the patients' pain. Despite the self-efficacy theory suggesting that the people's knowledge and attitude towards a specific behavior are the main determinants of their self-efficacy of this behavior, researchers have found an insignificant relationship between knowledge and perspective towards pain management and self-efficacy of pain management (Stanley \& Pollard, 2013).

One possible reason for this result may be that the researchers utilized "Pediatric Nurses' 'Knowledge and Attitudes Survey Regarding Pain," which may not be appropriate in identifying the actual clinical abilities that may not be correlated to the actual clinical practices (Manworren, 2000; Rieman \& Gordon, 2007). Another possible reason for this result could be the small sample size used. Thus, the current study utilizes a convenient survey to assess the determinants of self-efficacy regarding pain management by using a larger sample size $(\mathrm{n}=266)$.

The current study is premised on the effectiveness of self-efficacy theory which is a part of social cognitive theory as the basis of the theoretical framework. In essence, self-efficacy means an individual's belief that he or she can perform a specific task successfully (Bandura, 1994). According to this theory, the people self-efficacy mainly determinded by some factors. One of the most important factors is the cognitive factor which also called the personal factor (i.e. Knowledge, experiances, expectations and attitude). In this research, the relationship between the nurses knowledge, attitude and self-efficacy is examined. Figure 1 demonstrates the theoretical framework of this study.

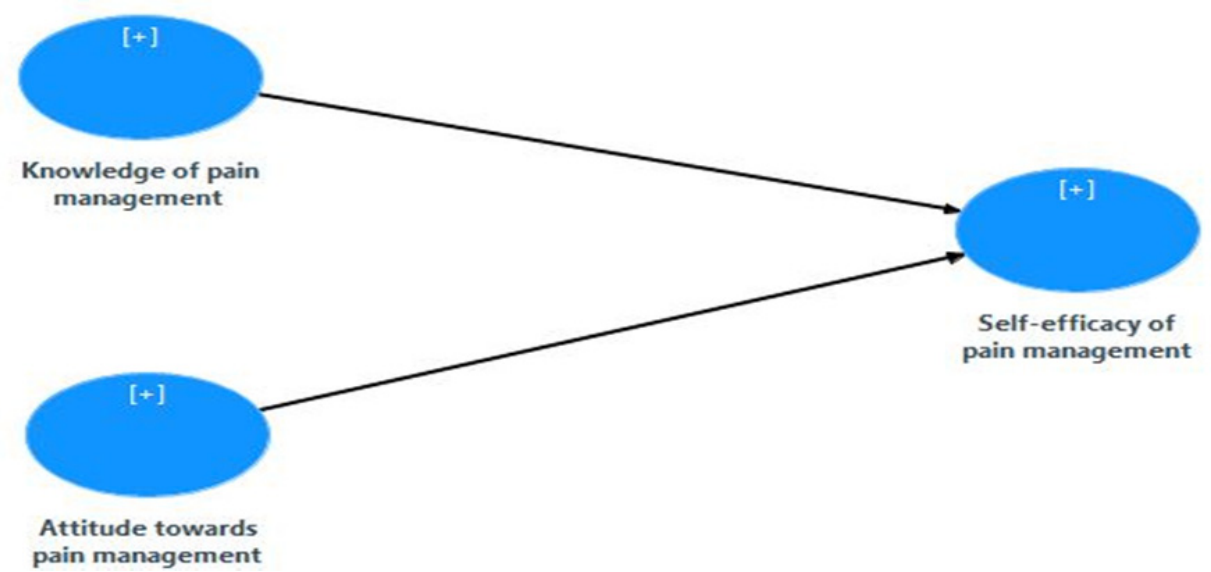

Figure 1. Theoretical framework

\section{Methodology}

The study is cross-sectional research that uses a correlational design, comprising a cluster sample of nurses in 13 public hospitals in the Central Jordan region. Before conducting the study, the researcher obtained the approval of the Ministry of Health, Jordan. They have registered professional nurses who are permanent employees at one of the 13 public hospitals. They were invited to participate in this study and were requested to fill in three instruments: the attitude towards pain management (McMillan, Tittle, Hagan, \& Laughlin, 2000); their knowledge of pain management (Ferrell, 2000); and self-efficacy of pain management (Chiang, Chen, \& Huang, 2006).

The first instrument used in the study is a questionnaire meant to measure nurses' attitude towards pain management (McMillan et al., 2000). This tool included 22 questions to measure the healthcare provider's attitude in managing patient discomfort. The instrument has an internal consistency of acceptable levels with a 0.7 Cronbach's alpha (Jackson, 2011). The second instrument in this survey is the knowledge of pain management (Ferrell, 2000). This instrument has a Cronbach's alpha of 0.80 that is an acceptable level of internal consistency. 
The tool also includes nine questions to measure the healthcare provider's knowledge of managing pain (Ferrell, 2000). The third instrument is the self-efficacy of pain management (Chiang et al., 2006). Also, the instrument comprises six questions about the nurse's belief in their ability to manage the patients' pain, and it has high internal consistency and Cronbach's alpha of 0.88 (pre-test) and 0.91 (post-test) (Chiang et al., 2006). Also, the Cronbach's alpha for this instrument is 0.81 (Stanley \& Pollard, 2013).

Questionnaires were distributed to the nurses at all hospitals by the person in charge of each facility. Out of the 600 questionnaires distributed, 329 were returned, representing a return rate of $55 \%$. However, 22 questionnaires were found to be incomplete, and therefore, not included in the statistical analysis.

The study used Statistical Package for Social Sciences (SPSS version 20) to obtain the descriptive information and the Partial Least Squares-Structural Equation Modeling (PLS-SEM version 3.0) to obtain the assessment of measurement model and structural model.

\section{Findings of the Study}

The number of nurses who contributed to the research was 266 nurses $(\mathrm{N}=266)$. Out of this total, 71 nurses ( $\mathrm{n}=71)$ participated from Military Hospitals and 236 nurses $(n=236)$ participated from hospitals under the Jordanian Ministry of Health. The mean age of the participants is 30 years. The majority of the participants are female $(60.2 \%)$, with experience of $1-5$ years $(31.2 \%)$ and holding a bachelor's degree in nursing $(86.8 \%) .78 .9 \%$ of the respondents had pain management experience, and $24.8 \%$ had attended a training course on pain management.

The findings (Table 1, Figure 2) reveal a statistically significant connection between the caregivers' acquaintance to agony management and their self-efficacy in managing the patients' anguish $(\beta=0.368, t=6.619, p<0.001)$. Table 1.1 shows that there is an immense connection between the nurses' attitude towards and their self-efficacy of distress management $(\beta=0.502, \mathrm{t}=10.119, \mathrm{p}<0.001)$. Lastly, Figure 3 reveals that the determinants of self-efficacy (knowledge and attitude) only explain 64\% of the nurses' self-efficacy of pain management $\left(R^{2}=0.64\right)$.

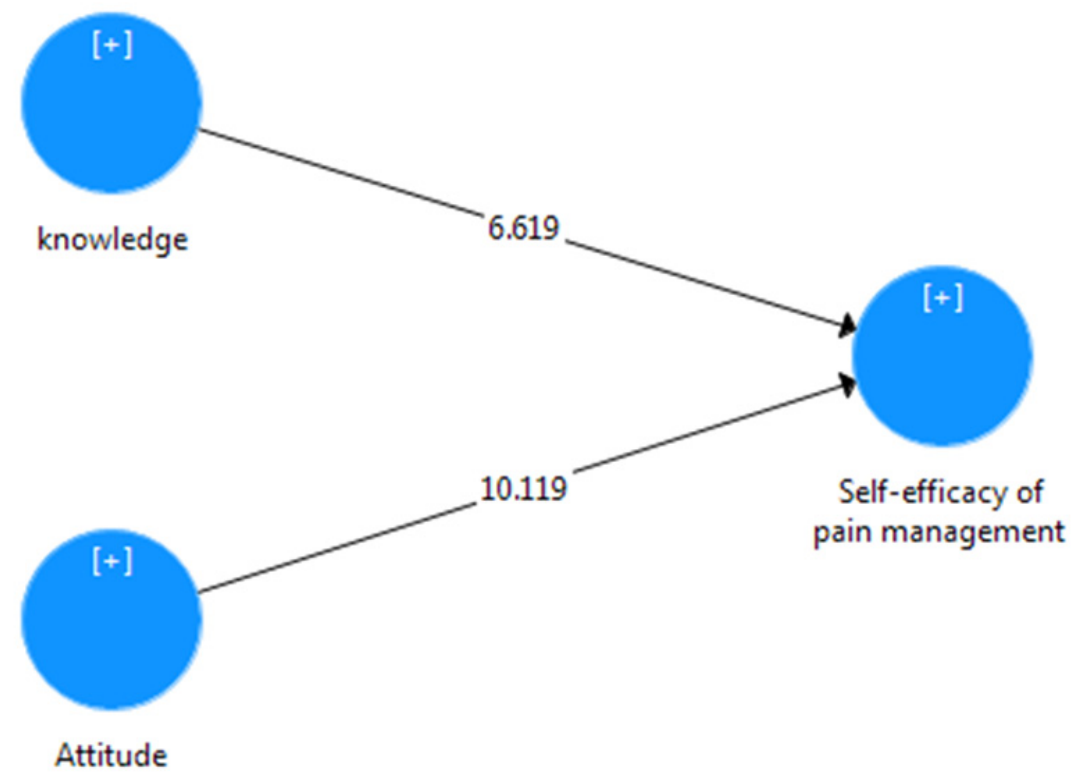

Figure 2. The structural model 


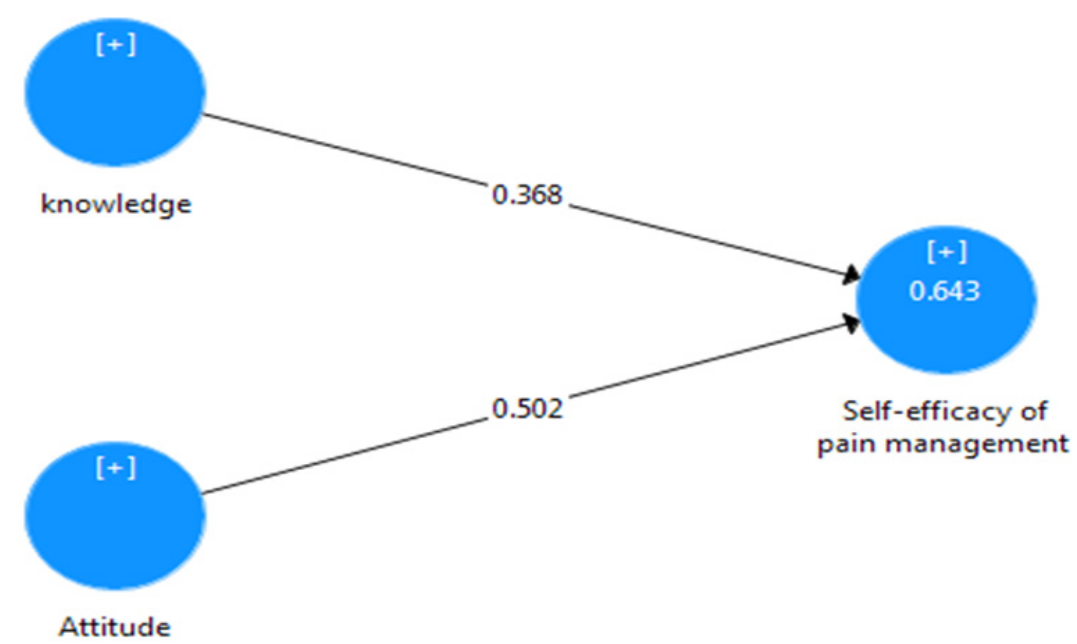

Figure 3. Measurement model

Table 1. Structural Model Assessment

\begin{tabular}{lllllll}
\hline Hypotheses & Relationships & Beta & Std. Error & t- value & p-value & Findings \\
\hline H1 & Attitude Towards Distress Management & 0.502 & 0.050 & 10.119 & $0.000^{* * *}$ & Supported \\
H2 & Knowledge of Pain Management & 0.368 & 0.056 & 6.619 & $0.000^{* * *}$ & Supported \\
\hline
\end{tabular}

Note. Endogenous Latent Construct $=$ Self-Efficacy of Pain Management

***Significant at 0.01 (1-tailed).

\section{Discussion \& Conclusion}

The primary objective of the survey is to investigate the association between knowledge, attitudes, and self-efficacy towards distress management for nurses by using the self-efficacy theory. The findings indicate a highly significant connection between self-efficacy of pain management and its determinants (knowledge and attitude). In essence, nurses feel confident when managing the patients' pain when they are adequately skilled. Also, agony management becomes active when the medical practitioner has the right attitude. As earlier indicated, it is the basic right of humans to be relieved from pain. Similarly, patients must be administered sufficient pain management. Therefore, it is crucial that hospitals take cognizance of the abilities of their nurses to undertake distress management practices. Also, medical facilities should focus on the nurses' skills and mindset by conducting training courses on pain management.

However, the research findings are not consistent with previous studies; for example, the study of Stanley and Pollard (2013) on the area of pain management. Nonetheless, it is consistent with the suggestions of the self-efficacy theory and consistent with the results of several studies in the medical field (Scherer \& Bruce, 2001; Sung, Huang, \& Lin, 2015).

The direct measures of the self-efficacy theory (knowledge and attitude) accounted for $64 \%$ of the variance in explaining the nurses' self-efficacy of pain management. While the results provide sound theoretical support for the use of the self-efficacy theory as a theoretical basis for the self-efficacy of pain management among nurses, further research is required to recognize what aspects contribute to the remaining $36 \%$ of the deviation in nurses' self-efficacy of distress management.

The limitations of the research include: a small sample population $(\mathrm{N}=266)$; the interviewees came from public hospitals only; and the voluntary participation of nurses. The outcome might, therefore, be skewed in that it does not represent the total nursing population in public hospitals in Jordan. Additionally, nurses who have little or no interest in pain may not have participated. Future research should include both the public and private hospitals to compare the results between the two sectors. Further, future research must focus on other issues that affect nurses' self-efficacy to pain management. 
Also, future research could examine the mediating effects of self-efficacy on the connection between knowledge and perspective towards pain management and agony management practices, besides looking into the direct relationship between self-efficacy of pain management and pain management practices of nurses.

\section{Competing Interests Statement}

The authors declare that there are no competing or potential conflicts of interest.

\section{References}

Adesoye, A., \& Duncan, N. (2017). Acute Pain Management in Patients with Opioid Tolerance. US Pharm, 42(3), 28-32.

Alpert, C. M., Smith, M. A., Hummel, S. L., \& Hummel, E. K. (2017). Symptom burden in heart failure: assessment, impact on outcomes, and management. Heart failure reviews, 22(1), 25-39. https://doi.org/10.1007/s10741-016-9581-4

Al-Zghoul, B. I. S. (2016). Determinants of nurses 'pain management practices in Jordan: The moderating role of patient's barriers (Doctoral dissertation, Universiti Utara Malaysia).

American Nurses Association. (2001). Code of ethics for nurses with interpretive statements. Nursesbooks. org.

Bandura, A. (1994). Self-efficacy. In V. S. Ramachaudran (Ed.), Encyclopedia of human behavior (Vol. 4, pp. 71-81). New York. NY: Academic Press.

Chiang, L. C., Chen, H. J., \& Huang, L. (2006). Student nurses' knowledge, attitudes, and self-efficacy of children's pain management: evaluation of an education program in Taiwan. Journal of pain and symptom management, 32(1), 82-89. https://doi.org/10.1016/j.jpainsymman.2006.01.011

Daibes, M. (2011). "A pain that ruins mountains": A case study of factors influencing postoperative pain management in two Jordanian hospitals (Doctoral dissertation, University of Warwick, Coventry, England).

Dunwoody, C. J., Krenzischek, D. A., Pasero, C., Rathmell, J. P., \& Polomano, R. C. (2008). Assessment, physiological monitoring, and consequences of inadequately treated acute pain. Journal of PeriAnesthesia Nursing, 23(1), S15-S27. https://doi.org/10.1016/j.jopan.2007.11.007

Ferrell, B. R. (2000). Family Pain Questionnaire. Retrieved from http://prc.coh.org/pdf/FPQTOOL.pdf

Gan, T. J. (2017). Poorly controlled postoperative pain: prevalence, consequences, and prevention. Journal of pain research, 10, 2287. https://doi.org/10.2147/JPR.S144066

Glajchen, M. (2001). Chronic pain: Treatment barriers and strategies for clinical practice. The Journal of the American Board of Family Practice, 14(3), 211-218.

International Association for the Study of Pain. (2010). IASP Declaration of Montréal. Retrieved from http://www.iasppain.org/Advocacy/Content.aspx?ItemNumber=1821

Jackson, E. B. (2011). Evaluating knowledge and attitudes of graduate nursing students regarding pain (Master dissertation, University of South Florida, Tampa, Florida, USA). Retrieved from http://scholarcommons.usf.edu/cgi/viewcontent.cgi?article $=4360 \&$ context $=$ etd

Jacobsen, R., Liubarskienë, Z., Moldrup, C., Christrup, L., Sjogren, P., \& Samsanaviciene, J. (2009). Barriers to cancer pain management: A review of empirical research. Medicina (Kaunas), 45(6), 427-33. https://doi.org/10.3390/medicina45060055

Khatib, S. K., \& Razvi, S. S. (2018). Nurses' Role in Acute Postoperative Pain Management: A Survey of 16 Tertiary Hospitals of Maharashtra. International Journal of Nursing Education, 10(1), 49-54. https://doi.org/10.5958/0974-9357.2018.00011.9

Manworren, R. C. (2000). Pediatric nurses' knowledge and attitudes survey regarding pain. Pediatric Nursing, 26(6), 610-610.

McCaffery, M., \& Pasero, C. (1999). Pain: Clinical manual (2nd ed.). St. Louis: Mosby.

McMillan, S. C., Tittle, M., Hagan, S., \& Laughlin, J. (2000). Management of pain and pain-related symptoms in

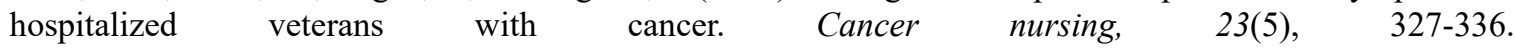
https://doi.org/10.1097/00002820-200010000-00001

Mędrzycka-Dąbrowska, W. A., Dąbrowski, S., Basiński, A., \& Pilch, D. (2016). Perception of barriers to postoperative pain management in elderly patients in Polish hospitals with and without a "Hospital Without Pain" Certificate-a multi-center study. Archives of medical science: AMS, 12(4), 808. 
https://doi.org/10.5114/aoms.2015.54768

Melotti, R. M., Samolsky-Dekel, B. G., Ricchi, E., Chiari, P., Di Giacinto, I., Carosi, F., \& Di Nino, G. (2005). Pain prevalence and predictors among inpatients in a major Italian teaching hospital. A baseline survey towards a pain free hospital. European Journal of Pain, 9(5), 485-485. https://doi.org/10.1016/j.ejpain.2004.09.010

Musgrave, C. F. (1990). Acute postoperative pain: The cause and the care. Journal of Post Anesthesia Nursing, 5(5), 329-337.

Rieman, M. T., \& Gordon, M. (2007). Pain management competency evidenced by a survey of pediatric nurses' knowledge and attitudes. Pediatric Nursing, 33(4), 307-312.

Sawyer, J., Haslam, L., Robinson, S., Daines, P., \& Stilos, K. (2008). Pain prevalence study in a large Canadian teaching hospital. Pain Management Nursing, 9(3), 104-112. https://doi.org/10.1016/j.pmn.2008.02.001

Schechter, N. L., Berde, C. B., \& Yaster, M. (Eds.). (2003). Pain in infants, children, and adolescents. Lippincott Williams \& Wilkins.

Scherer, Y. K., \& Bruce, S. (2001). Knowledge, attitudes, and self-efficacy and compliance with medical regimen, number of emergency department visits, and hospitalizations in adults with asthma. Heart \& Lung: The Journal of Acute and Critical Care, 30(4), 250-257. https://doi.org/10.1067/mhl.2001.116013

Stanley, M., \& Pollard, D. (2013). Relationship between knowledge, attitudes, and self-efficacy of nurses in the management of pediatric pain. Pediatric nursing, 39(4), 165-171.

Sullivan, L. M. (1994). Factors influencing pain management: A nursing perspective. Journal of post anesthesia nursing, 9(2), 83-90.

Sung, S. C., Huang, H. C., \& Lin, M. H. (2015). Relationship Between the Knowledge, Attitude, and Self-Efficacy on Sexual Health Care for Nursing Students. Journal of Professional Nursing, 31(3), 254-261. https://doi.org/10.1016/j.profnurs.2014.11.001

The South African Society of Anaesthesiologists. (2009). South African Acute Pain Guidelines. Southern African Journal of Anaesthesia and Analgesia, 15(6), 1-120.

Von Roenn, J. H. (2001). Are we the barrier?. Journal of Clinical Oncology, 19(23), 4273-4274. https://doi.org/10.1200/JCO.2001.19.23.4273

\section{Copyrights}

Copyright for this article is retained by the author(s), with first publication rights granted to the journal.

This is an open-access article distributed under the terms and conditions of the Creative Commons Attribution license (http://creativecommons.org/licenses/by/4.0/). 